\title{
Necrotising aspergillosis complicating fulminating viral pneumonia
}

\author{
A G JARIWALLA, A P SMITH, AND G MELVILLE-JONES
}

From Llandough Hospital, Nr Penarth, South Glamorgan

Post-influenzal bronchopneumonia is commonly bacterial, usually pnuemococcal or staphylococcal, though in the 1957 pandemic fatal cases of pure viral pneumonia were recorded. 1 We report a case of necrotising or invasive aspergillosis complicating a fulminating viral pneumonia in a 14-year-old girl.

\section{Case report}

After a holiday in Devon in September 1977, a previously fit 14-year-old schoolgirl developed headaches, myalgia, sore throat, and fever. She was given a seven-day course of tetracycline, followed by four days on magnapen, without any improvement. Over the 24 hours before admission to hospital she developed progressive dyspnoea and severe respiratory distress. On examination she was febrile $\left(39 \cdot 8^{\circ} \mathrm{C}\right)$, cyanosed, confused, and had bilateral coarse inspiratory and expiratory lung crackles. She was well perfused and normotensive.

Chest radiograph showed extensive bilateral confluent nodular infiltration. Haemoglobin was $9.9 \mathrm{~g} / \mathrm{dl}$, and white cell count $22.1 \times 10^{9}$ per litre $-96 \%$ neutrophils, $3 \%$ lymphocytes, and $1 \%$ monocytes. Blood film was normocytic normochromic. Erythrocyte sedimentation rate was 86 in one hour (Westergren). Platelet count was $440000 \mathrm{~mm}^{3}$, reticulocytes less than $1 \%$. Arterial blood gases showed $\mathrm{PaO}_{2} 8 \cdot 1 \mathrm{kPa} \mathrm{PaCO}_{2} 7 \cdot 6 \mathrm{kPa}$ on room air. Parainfluenzal complement fixation test was $1: 32$ on two occasions. Bronchial secretions, although purulent, did not reveal respiratory pathogens or acid-fast bacilli. Fluorescent antibody test against Legionella pneumophila was negative. The following tests were normal: bone marrow histology, electrolytes, serum and urine osmolality, electrocardiograph, Coombs' test, Toxoplasma dye test, serial blood cultures, cold agglutinins, histology of lung aspirate obtained via bronchoscopy, liver function tests, Paul Bunnell, immunoglobulins, protein electrophoresis, urine for acid-fast bacilli and pathogens, and blood sugar. Various other investigations for disseminated neoplasm, collagen diseases, pulmonary alveolar proteinosis, and disseminated intravascular coagulation, were negative. Precipitating antibodies to Aspergillus fumigatus, reported after the patients death, were strongly positive.

The patient was ventilated with intermittent positive pressure and given ampicillin, cloxacillin, tetracycline, gentamicin, and amantadine. Methyl prednisolone (4g daily for eight days) was also given. She developed

Address for reprint requests: Dr AG Jariwalla, Department of Medicine, University Hospital of Wales, Hearth Park, Cardiff. diabetes mellitus, which was thought to be the result of steroid therapy, and was well controlled on insulin. High ventilatory pressures and oxygen concentration were necessary to maintain adequate blood gases. A right spontaneous pneumothorax was promptly managed with an intercostal tube connected to an underwater seal. Her condition deteriorated further, and she died 10 days after admission to hospital.

At necropsy, both lungs were extensively consolidated. There was fibrinopurulent exudate on the pleural surface on both sides extending into the fissure. The cut surface of the right lung (fig 1) revealed haemorrhagic consolidation of the lung. On this background innumerable small yellow necrotic lesions, some acinar and some circular in

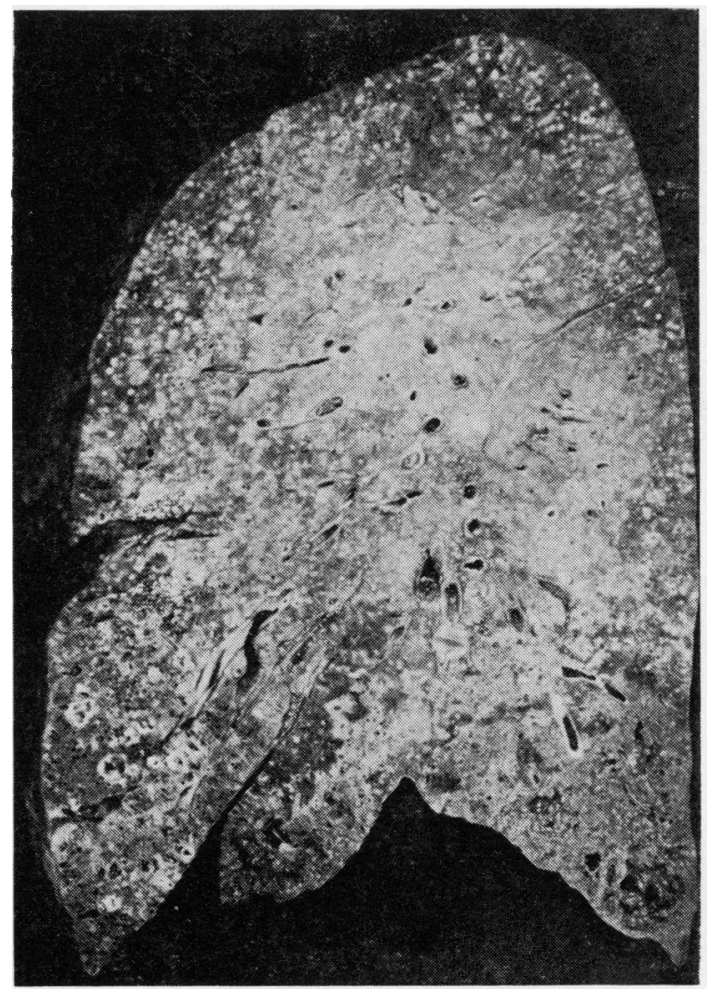

Fig 1 Cut surface of the lung showing a background of haemorrhagic consolidation with numerous necrotic foci $1 \mathrm{~cm}$ to $3 \mathrm{~cm}$ in diameter. Some of the larger foci show central cavitation. 


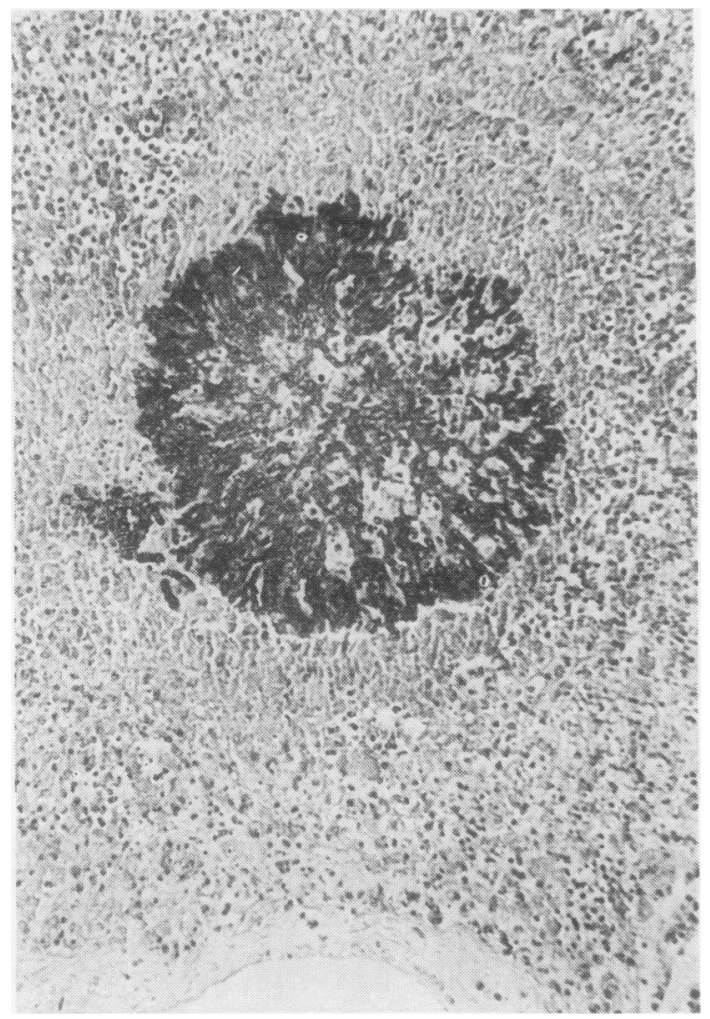

Fig 2 Mycelial colonies of $A$ fumigatus in necrotic lung tissue. PAS, original magnification $\times 70$.

shape, from 1 to $3 \mathrm{cms}$ in diameter, were present. Some of the larger lesions showed some central cavitation. Histology (fig 2) showed diffuse necrotising aspergillosis on a background of viral pneumonia. Typical hyphae were seen and Aspergillus fumigatus was cultured from swabs. There was also necrosis of alveolar lining cells with some hyaline membrane formation. There was no evidence of any other organ involvement with Aspergillus.

\section{Discussion}

Fatal cases of primary necrotising aspergillosis are rare in children. When described ${ }^{2}$ there is circumstantial evidence that they follow prolonged and close contact with Aspergillus species in a contaminated environment, usually on a farm. We were unable to obtain such a history in our patient. Diffuse pulmonary aspergillosis usually complicates a pre-existing disorder, either of the lungs themselves, or as an opportunist pathogen in compromised host.

We believed that the patient's initial symptoms were of influenza, and the admission radiograph suggested a $\overline{\bar{\omega}}$ fulminating viral pneumonitis. Similar radiological $\frac{\widehat{\phi}}{\top}$ appearances would be seen in infection caused by Pneumocystis carinii, pulmonary alveolar proteinosis, acute interstitial pulmonary fibrosis, acute collagenosis, $\rightarrow$ pulmonary oedema, and reticuloses. These conditions? were systematically excluded as far as possible.

Significant respiratory pathogens were not isolated $\vec{\omega}$ from tracheobronchial secretions until two days before death. However, in view of her deteriorating condition, $a \times$ wide range of antibiotics and methyl prednisolone were $\omega$ given. These drugs have been thought to be of aetiologicalcu significance in pulmonary aspergillosis, but the subjectiv remains controversial. Abbot et $a l^{3}$ described a case of $\vec{G}$ pulmonary (cavitating) aspergillosis after post-influenzalo bronchopneumonia during an influenza epidemic. This_ patient had received antibiotics, but died 16 days after $z$ admission. However, cases coming to necropsy, when evidence of aspergillosis is discovered, have died almost $\frac{\widehat{\rho}}{\supset}$ invariably from serious underlying disease. ${ }^{4}$ It would be $\overrightarrow{ }$ fair to suggest, from evidence so far, that any previous $@$ treatment with steroids or antibiotics is coincidental so. far as the fungus is concerned.

Rapid development of necrotising aspergillosis in this previously healthy patient is of interest. The diagnosis of this condition during life is difficult. Precipitins, reported after the patient's death, were strongly positive to Aspergillus fumigatus but negative to $A$ niger, Candida albicans, Micropolyspora faeni, and mouldy hay dust, but $\vec{\sigma}$ precipitins may be absent in this syndrome. ${ }^{5}$ At no stage 3 was Aspergillus isolated from the bronchial secretions.? Transbronchial lung biopsy may prove to be the onlyo way of diagnosing the condition early enough for antifungal treatment to be applied.

\section{References}

1 Mulder J, Hers JF. Influenza. Groningen: Wolters-Noordhoff, 1972; 53.

2 Strelling MK, Rhaney K, Simmons DAR, Thompson J. Fatal acute pulmonary aspergil-o losis in two children of one family. Arch Dis Child 1966; 41:34-43.

3 Abbott JD, Fernando HVJ, Gurling K, Meade을 BW. Pulmonary aspergillosis following postinfluenzal bronchopneumonia. $\mathrm{Br} \mathrm{Med} J$ 1952; م 1:523-5.

4 Symmers WStC, The occurrence of deep-seated fungal infections in general hospital practice inc Britain today. Proc $R$ Soc Med 1964; 57:405-11.0

5 Young RC, Bennett JE. Invasive aspergillosis. Am Rev Respir Dis 1971; 104:710-6. 